Article

\title{
An Accord in/on Kantian Aesthetics (or the Sensus Communis: Attunement in a Community of Diverse Sites of Purposiveness)
}

Ryan J. Johnson

\begin{abstract}
Kant's Critique of Judgment is a storehouse full of provocative concepts and structures, which is why, since at least the 1970's, many contemporary Kant scholars and philosophers of other sorts have attempted to mine and explicate this text to varying degrees of success. Among these concepts and structures, there are a few that continue to evade complete elucidation. One of the most well tread, albeit still contested, grounds that appears in the third Critique is "purposiveness without purpose." Picking up from some recent interpretations of Kantian aesthetics, I contend that it is possible to discover at least three forms of purposiveness without purpose in aesthetic judgments. A second concept, the sensus communis, I will contend, is as important as the three sites of purposiveness without purpose. In fact, I will show how the sensus communis, in its ternary form, can be mapped onto the three sites of purposiveness without purpose; the two concepts cannot be separated. Finally, this mapping will allow for an attempt at what I could refer to as an "inconstruction" of the Deduction of Aesthetic Judgments that will engage many of the long-standing questions surrounding this text.
\end{abstract}

Key words: Kant, Critique of Judgment, sensus communis, aesthetics

The philosopher seeks to hear within bimself the echoes of the world symphony...he is contemplative perceptive like the artist... a seeker of purposes. $-F$. Nietasche

K ant's Critique of Judgment is a storehouse full of provocative concepts and structures. Since the 1980's, many Kant scholars and philosophers varying degrees of success. Among these, there are a few that continue to evade complete elucidation. Rather than attempting to reduce these rich ideas down to single definitions in the hopes of some future success, I will attempt an experiment.

One of the most well tread, albeit still contested, grounds that appears in the third Critique is the use of the concept of "purposiveness without 
purpose." Utilizing some recent interpretations of Kantian aesthetics, and to risk cutting things up in an unjustified manner, I contend that it is possible to discover at least three forms of purposiveness without purpose in aesthetic judgments. These three forms are distinguished in terms of their locations. The beginning of the paper will cover these three sites of purposiveness without purpose.

A second, perhaps even more confusing although much less appreciated, concept is the notion of a sensus communis. While it is certainly impossible to read the third Critique without engaging the notion of purposiveness without purpose, it seems possible, as some have demonstrated, to almost completely expunge the sensus communis from text. This strikes me as a great mistake. The sensus communis, I will contend, is as important as the three sites of purposiveness without purpose. In fact, I will show how the sensus communis, in its ternary form, can be mapped onto the three sites of purposiveness without purpose; the two concepts cannot be separated, according to this reading. This mapping will allow for an attempt at what I could refer to as an "inconstruction" (rather than a reconstruction or deconstruction) 1 of the Deduction of Aesthetic Judgments that will engage many of the long-standing questions surrounding this text.

\section{Three Sites of Purposiveness: Purposiveness in the From the Object}

The first occurrence of purposiveness without purpose is located in the object itself. This is a standard interpretation of the third moment in Critique of Judgment, the moment of relation: to say that the purposiveness that Kant uses as the axis or point around which the theoretical discussion revolves and gains momentum is located directly on the object. While the first two moments, the moments of quality and quantity, seem to concern more the activity in the subject, or at least the effect of the representation of the object in the subject, the third moment brings the object (always seen as the representation of the object) back into play. Kantian aesthetics, as is well known, departed from previous aesthetic theories in that that which is considered aesthetic is no longer solely the object or merely the subject. The aesthetic part, rather, occurs in the judgment of the relation between the subject and the object. Neither pole - subject or object - alone is able to constitute the aesthetic element. The two, rather, must be taken together. The third moment, then, acts as the return along this relational line between the poles: that is, the object is seen as purposive.

1 This is simply a tentative methodology of reading the history of philosophy that is neither a reconstruction or kind of revisionism nor a deconstruction along the lines exhibited in the writings of Jacques Derrida. Rather, an inconstruction is a way of using a thinker's set of concepts as melodies or conceptual structures that provide openings and opportunities for experimentation with sets of ideas or concepts. 
The focus on the object in this middle moment, as it were, pulls the discussion from the subject to the object, if only momentarily. (This point, however, will be raised as a question rather than asserted as a conclusion.) In short, what it is about the object that acts as the occasion on which the subject can judge aesthetically, and thus can feel pleasure in the beautiful object, is its form of purposiveness. The object, in itself, seems to be directed toward some end. Something about the object, something about its form or structural coherence, seems to strive or aim towards a goal. The issue, or the special quality of this form of purposiveness that gives rise to aesthetic pleasure rather than the pleasure in the application of the concept, is that the purpose, or that towards which the object seems to be aimed, cannot be found. Hence, the notion of purposiveness-without-purpose. Perhaps, strangely enough, Derrida, although he is know for his particularly abstruse (albeit clever) style of writing, sums up this quality of the object with concinnity and clarity. This purposiveness-without-purpose is the "feeling of beauty, [of] attraction without anything attracting, fascination without desire... of an oriented, finalized movement harmoniously organized in view of an end which is never in view, seen, an end which is missing."”2 This suggests that the object in itself, due to its very own internal organization, seems to open up the opportunity for pleasure in aesthetic objects. It remains to be seen, however, what exactly it is about the form of the object that opens up this opportunity. What is it, to tie it into Kant's own example, that is revealed in the opening up of the petals of a tulip? What, in short, does Kant mean by 'form' in the form of purposiveness or finality of the tulip or the painting?

This question is hotly contested. Paul Guyer, to take one influential example, tries to sidestep the issue completely in order to highlight what he takes to be the more essential features of Kantian aesthetics. ${ }^{3}$ Hannah Ginsborg makes an even stronger dismissing move and rarely, if ever, even mentions Kant's insistence on purposive form. ${ }^{4}$ Almost all of these accounts, while certainly merited in many other respects, miss something important and lasting about Kantian aesthetics. This is why I would argue that Rachel Zuckert puts forward the most convincing account of Kant's formalism in a recent article. ${ }^{5}$ Kant's formalism, Zuckert argues, is more of a "whole-formalism" rather than a "property-formalism." To work backwards, a generic account of property-formalism (seen in, for example, Guyer's or Ginsborg's rather negative accounts) holds that it is the relations among certain dominant spatio-

2 Jacques Derrida, The Truth in Painting, trans. by Geoff Bennington and Ian McLeod (Chicago:The University of Chicago Press, 1987), 86-87; emphasis in the original.

${ }^{3}$ See Paul Guyer, Kant and the Claims of Taste (Cambridge, U.K.: Cambridge University Press, 1997), chapter 6.

${ }^{4}$ While this is true in most of Ginsborg's work, see her articles "On the Key to Kant's Critique of Taste," Pacific Philosophical Quarterly 72(4) (1991): 290-313, or "Purposiveness and Normativity," in Hoke Robinson ed., Proceedings of the Eighth International Kant Congress (Milwaukee: Marquette University Press, 1995), volume II, 453-460.

5 Rachel Zuckert, "The Purposiveness of Form: A reading of Kant's Aesthetic Formalism," Journal of the History of Philosophy, (2006). 
temporal properties in an aesthetic object that makes the object beautiful. This variety of formalism, for example, contends that it is a certain decontextualizable property of objects that contains the aesthetic relevance of the aesthetic object.

Kant is not, however, a property-formalism. Why? For one, to say that certain identifiable properties act as the opportune occasions for aesthetic judgments risks the introduction of concepts and conceptual generalization. If it were possible to locate and list certain "beautiful properties" of an object, then these properties alone, without reference to the coherence of the object as a whole, would bring about pleasure in the beautiful. This means that it would be possible to develop a concept that acts as the general class of "beautiful properties" and from which particular instantiations of these properties could be determined as beautiful objects. Moreover, if it were the case that only the abstractable formal properties of objects occasion the aesthetic experience, then a completely non-aesthetic object would have to be beautiful. ${ }^{6}$ This means, in short, that some properties serve as either (or both) necessary or (and) sufficient conditions for beauty. All of this, however, runs against the grain of much of the Third Critique. For, Kant says, an aesthetic judgment must find no recourse to concepts. ${ }^{7}$ If judgment did refer or at least defer to concepts, it would become a determinative judgment and cease being a reflective judgment. Although this might not be a completely convincing argument against Kant being a property-formalist, it does certainly gesture in the direction of Zuckert's reading of Kant as a whole-formalist. But what is whole-formalism?

To use Zuckert's own words as a way of opening the definition, "when Kant claims that the beauty in an object lies in its purposive form, he is (plausibly) claiming that beautiful objects are characterized by an organic or purposive unity - a unity of diversity."8 In short, Zuckert argues that the holistic coherence of an organism acts as an analogical picture that underpins, and can be used as an explicatory account, of the formalism in aesthetic objects. Moreover, this argument for the whole-formalism that appears in the Third Critique is further corroborated by the fact that Kant himself uses this analogical connection as a way to connect the two major divisions of the text: the Critique of Aesthetic Judgment and the Critique of Teleological Judgment. ${ }^{9}$

${ }^{6}$ It should be noted, however, that this is not, in itself, problematic. Part of the deduction will claim that all objects are potentially aesthetic. See the last section of the paper for more on this.

${ }^{7}$ Rachel Zuckert, in her Kant on Biology and Beauty, attenuates this claim. She contends that concepts do play a role in aesthetic judgment it is just that concepts play a merely indicative role rather than a determinative role. See Rachel Zuckert, Kant on Biology and Beauty (Cambridge: Cambridge University Press, 2007), 184, 199, 200, 203, and 297 for her rather convincing arguments in favor of the inclusion of concepts in aesthetics judgments.

8 Ibid., 610.

${ }^{9}$ Many commentators have, however, argued that such an analogical connection is either unconvincing or superficial, especially when one considered the tenuous relationship between subjective purposiveness and objective purposiveness. See Hannah Ginsborg, 
Let us now explore the similarities between the structural coherence of organisms and the whole-formalism of objects of beauty.

According to Kant, there are at least two unique categories of objects offered by nature: objects that can be mechanically explained and objects that refuse such a Newtonian explanation, namely organisms. Perhaps the main distinguishing feature of the two types of natural objects is that the former is intrinsically divisible. Organisms, on the other hand, cannot be so intrinsically divided without altering (read here: killing) it. As Zuckert says, "[e]ach part of an organism matters to the functioning of the whole and seems to belong to the organism...each part is what it is, does what it does, only in the context of the whole."10 It is not possible, for example, to just swap out a hand or a leg without drastically altering, if not destroying, the functioning (one might dare say life) of the organism as a whole. Each part of the organism - hand, head, leg - are contingent properties - they could have been a wing, shell, or hoof but they are necessary in relation to every other property in terms of the whole. Each of the properties is not relevant unto themselves, but only insofar as they interact with each other for the sole purpose of the whole (the survival of the organism). This contrast yet complementing of the necessarily interrelated parts of the organism is similar to Kant's whole-formalism.

Similarly, the parts or properties of an aesthetic object are meaningful not merely in themselves but only insofar as they constitute the structural coherence of the whole work of art. The line or curve, just like the hand or foot, cannot be abstracted from the whole artwork and still retain the same aesthetic significance. The parts are contingent - the line could certainly have curved to the left rather than to the right - but, in terms of the whole work, each part is necessary. Similarly, the formal meaning of each of the parts depends solely on the placement of the parts as they interrelate, or contrast yet complement, each other in their constitution of the whole. The whole, in short, is more than the sum of its parts. And it is this whole that is the formal quality that Kant refers to when he declares that one should pay attention to the form of the object alone. The artwork is beautiful, then, because the diversity of parts of the artwork are unified through the form of the whole: hence, wholeformalism.

If this account of Kant's brand of formalism is correct, then it is safe to say that the first site of purposiveness without purpose, namely, the purposiveness in the object itself, is conveyed via the way in which all the parts of the work "hang together" (zusammenhalten). The way in which all the heterogeneous parts of the work simultaneously contrast yet complement each other leads the subject to receive the object as directed towards some end, it is just that that end towards which it seems to be directed cannot be found.

"Reflective Judgment and Taste," in Nous, 24:1 (1990), 63-78 63-78, for a full list of these complaints.

10 Zuckert, Kant on Beauty and Biology, 610. 


\section{Purposiveness in the Object as Directed towards the Subject}

A second site of purposiveness builds off of the first location. While the purposiveness that seems to unify the diversity of parts of the aesthetic object in terms of the whole is located in the represented object alone, the second location takes a step further in claiming that the object is also purposive for us, for our taking pleasure in the object. As Kant himself says, "the liking...can be [based] on nothing but the subjective purposiveness in the presentation of an object, without any purpose... and hence the mere form of purposiveness, insofar as we are conscious of it, in the presentation by which an object is given to us." 11 It is clear from the text that it is also possible to locate a site of purposiveness without purpose that is directed towards us, as it is given to us. Let's look at the structural similarity of two sides of the act of giving - the giver and the receiver - before we examine this concept of giving.

Due to the particular organization and form of our cognitive capacities - cognition in general, as Kant is fond of saying - and due to the pleasure we take in the aesthetic object, it seems as if the object were intended to bring about a pleasure in the subject: our "mental machinery," as it were, and the formal coherence of the diversity of parts in certain objects seem to harmonize. ${ }^{12}$ It's as if our minds and certain objects, aesthetic objects, were cut from the same cloth.

To take a step back and situate this within the larger argument of Critique of Jugment. although much of human life is spent apprehending, subsuming, and determining the objects encountered in the world, there are certain moments when the application of rules and laws simply fails. It is in these moments, these temporary ruptures of cognition, that act as moments of exposing ourselves to objects. These indeterminate encounters with aesthetic objects act as a worldly coherence between the subject and the object, the receiver and the giver, respectively. This harmonic coherence would not be possible, however, if the object were of a completely different nature than the subject. If the two were completely different, then there would be no communication of any kind, neither determinate nor indeterminate. The object, in these singular moments when the subject is no longer silencing the object through the application of the rules of the understanding, speaks to us in what

11 Immanuel Kant, Critique of Judgment, trans. by Werner S. Pluhar (Indianapolis: Hackett Publishing Company, 1987), 11; emphasis in the original.

12 Robert Pippin has an interesting account of exactly what it is about certain objects that seem suitable for our lives as cognitive beings. Pippin argues, convincingly so, that the aesthetic objects are suitable for humans insofar as humans as normative creatures. As Pippin says, "aesthetic delight must be understood as a distinct, pleasurable sense of the suitability of the natural world to our unique capacity as norm-instituting and norm-following beings." This placement on the suitability of the natural world for our status as normative creatures strikes me as an interesting, albeit uncertain, location of the exact nature of the kind of suitability for which Kant is arguing. See Robert Pippin, "The Significance of Taste: Kant, Aesthetic, and Reflective Judgment," in The Journal of the History of Philosophy, 34:4 (1996), 549-569. 
could be referred to as a "ciphered voice," a voice that cannot be deciphered by the normal means of determinative subsumption. ${ }^{13}$ For a cipher is simultaneously, on the one hand, a nonentity or pure emptiness, at value zero, that is, the without end, the lacking of the meaning of an end - and, on the other hand, a coded message, a series of inscriptions that evade definite inscription - that is, finality or purposiveness itself, and a movement towards the end of meaning. Due to a lack of determinate key that would decipher this language, the voice of nature (which is certainly a quiet voice, a voice that we can and should pick up on) is usually drowned out in the activities of theorization and moral reasoning. In the end, although we cannot conceptually understand it, we can intuitively feel it. In this singular representation that stands beyond the walls of theory and morality, we sense a forgotten familiarity, a pre-conceptual familiarity that was there all along. Despite, or perhaps because of, this ciphered voice, the object is seen as suitable to my faculty of judgment. This is evinced by the pleasure in the subject's reception of the gift of the object.

To return to the given - that which is given that acts as the direction arrow linking the object and the subject, the giver and the receiver - Derrida also says speaks of this linking as a giving: "It [the purposiveness located in the object] gives the beautiful." 14 We have just examined the effects of the gift on the subject. It is now time to consider this act of giving itself.

As was said, what is given by the object is actually a part of myself, albeit the part that exceeds the conceptual and ethical parts of myself. What is given is a confrontation with the ends of myself through a particular engagement which is a unique type of relationship with the object. This is the sense that the purposiveness of the object is for the subject. Or maybe, the gift is a trace of myself that leads me out of myself in my ordinary mode of truthonly cognition or moral reasoning, and into myself as attuned to the aesthetic object. As Lyotard says, this is the case of the "mind discovering that it can do something other than will and understand. Be happy without ever asking for it or conceived it." 15 Hence the purposiveness that seems to be directed towards me, since I am the intentional object of the form of finality of the represented object, seems to serve my own purposes (although to claim such a destination would bandage the cut of the without separating purposiveness from the purpose and lead us back into the complex intrigues of science and morality).

What is the status of this giving, then? It is a giving without a gift, a giving without determinative reception, a purposiveness without a definite purpose. It is the reception of a gift that is not seen as a gift but is received as if it were a gift intended to be received as a gift, by the subject. "It is we who

\footnotetext{
13 Jacques Derrida, "Economimesis," Diacritics, 11 (Summer, 1981), 3-25. Kant also mentions this cipher at Critique of Judgment, $\int 42$ : "the true interpretation of that cipher through which nature speaks to us figuratively in its beautiful forms."

14 Derrida, Truth in Painting, 90; emphasis in the original.

15 Jean-Francois Lyotard, "Sensus Communis," in Judging Lyotard (New York: Routledge, 1992), 5.
} 
receive nature with favor, not nature that favors us." ${ }^{16}$ The gift then has the status of having run errant, of a natural and wild errancy, for its arrival came and passed long ago; but the subject was too wrapped up with its own scientific intrigues and moral willing. Since this early denial of the arrival of the gift, it has wandered freely, a beauty free from any economic circulation: pulchritude vaga, par excellence. ${ }^{17}$ The gift can now only be received as if it were intended for the subject, as if the subject were the intended/intentional object, although this supposed directionality could always have been due to the error brought by this very errancy. As Kant himself says, "what counts in beauty is not what nature is, nor even what purpose it has for us, but how we receive it"18 But for this very reason, the gift is now pure, which nicely coheres with the purity of Kantian aesthetic judgments. It is pure because, "when it is a question of tasting beauty, [it] is precisely a feeling of pleasure... which doesn't come to fill up a lack, nor to fulfill any desire at all. A pleasure before any desire...not even mediated by...our way of remembering and anticipating." ${ }^{19}$ The gift appears by surprise, without an anniversary or special occasion calling out for it, without a favor to be repaid, without a sin or evil deed needing to be forgiven. The purity of this gift, which is also a gift of purity, stems from the purity of the separation (the cut) between purposiveness and purpose. Thus, there is a second site of purposiveness without purpose alongside what was seen in the object itself.

\section{Purposiveness in the Pleasure in the Subject}

At this point it should be clear that the notion of purposiveness can be located in a number of different senses: there is the appearance of purposiveness in the object as represented in itself, and there is a purposiveness in the object as given for, and received by, the subject. But there is at least one more sense of purposiveness in Kant's aesthetics. It is possible to locate a third kind of purposiveness in the subject, or to be more precise, in the pleasure that is experienced by the subject. Kant supports this location in saying "the judgment is an aesthetic one regarding the harmony, within the subject, of the imagination's presentation of the object with the essential principles of judgment as such." 20 Perhaps the best way into this third sense of purposiveness is to return to Rachel Zuckert. ${ }^{21}$

\footnotetext{
${ }^{16}$ Kant, Critique of Judgment, $₫ 58$; emphasis is mine.
}

17 Vaga, although Kant translates the term as 'free,' also implies roving or wandering, or even errancy from an intended path. Thus the telos towards which the gift was originally aimed has lost its attractive fore. But despite this lack of end, the gift still retains the form of finality, it still seems to be directed towards some end, it's just that that particular end cannot be found.

18 Kant, Critique of Judgment, $\ 58$.

${ }^{19}$ Lyotard, "Sensus Communis," 5.

${ }^{20}$ Kant, Critique of Judgment, \58.

21 Rachel Zuckert, "A New Look at Kant's Theory of Pleasure," in The Journal of Aesthetics and Art Criticism, 60:3 Summer (2002), 239-252. 
To see how and why Zuckert reorients the approach to aesthetic pleasure, and pleasure in general, it is useful to see how Kant actually defines pleasure himself. He says: pleasure is the "consciousness of a presentation's causality directed at the subject's state so as to keep him in that state." 22 If we are to take Kant at his word, or at least only at his words, then pleasure is, Zuckert argues, both intentional and formal. This is where Zuckert successfully, I would argue, overcomes Guyer's interpretation of pleasure. While Guyer claims that Kantian aesthetic pleasure is "agreeable sensation" in the sense of a sort of an ambiguous, brute, feeling, Zuckert highlights the a priori principle that led Kant to discover the structure of one of man's three mental faculties. ${ }^{23}$ For Zuckert, pleasure in the subject is intentional in that it is "apparently a mental state that is 'about' another mental state." 24 One state of mind takes as its intentional object another state of mind, and the pleasure is located in this awareness of this other mental state preservation. ${ }^{25}$ Noting Kant's use of different German words for 'object' furthers this intentionality thesis. Both of the German words Gegenstand and Objekt are translated into English as 'object,' but they refer to different kinds of objects. Gegenstand refers to an actual determinate object of knowledge; but Objekt refers to a "'mere' intentional object of a presentational state." 26 Since the object seen as the intentional object of pleasure is this second sense of 'object,' the German Objekt, it is clear that the object of pleasure is another mental state. Moreover, since the presentation of the object "causes" us to want to keep this presentational state, this pleasure is purposive; pleasure arises in the wanting to "linger in our contemplation of the beautiful, because this contemplation

${ }^{22}$ Kant Critique of Judgment, $\ 10$.

${ }^{23}$ Guyer, Kant and the Claims of Taste, 104-105.

${ }^{24}$ Zuckert, “A New Look,” 240.

25 Henry Allision, in his Kant's Theory of Taste, finds this definition of pleasure counterintuitive. As he says, "a subject endeavors to preserve a state because it is pleasurable, not that the preservation is what makes the state pleasurable." Allison connects Kant's definition of pleasure with the definition of purposiveness. In short, Allison wants to define pleasure as our liking of a representation and not merely the awareness of it. This strikes me as simply a case of misreading. For example, Allison cites only part of Kant's definition of pleasure: "[c[onsciousness of an representation's causality." But he does not include the rest of the quote, which reads "directed at the subject so as to keep him in that state. So, as once you look at the entire quote, it because clear that pleasure is not defined as simply an awareness of a representation; rather, pleasure is an awareness of a representation (another mental state, on the intentionality view) insofar as the representation is purposive. As Kant says, the pleasure is in the "presentation causality." And is it not the case that a presentation's causality is its purposiveness without purpose, its suitability for us? Moreover, Allison rightly points out that the state itself is inherently pleasurable. But what is it about the state that is pleasurable if not its purposiveness or its "causality directed at the subject"? See Henry Allison, Kant's Theory of Taste: A Reading of the Critique of Aesthetic Judgment (Cambridge, UK: Cambridge University Press, 2001), 122.

26 Zuckert, "A New Look," 240. Etymologically, this difference is even clearer. Gegenstand can be broken down into gegen, which means against, opposed to, or towards, and stand, which means stand, stand or stood up. So, an object (Gegenstand) is that which is standing out there against the subject. 
reinforces and reproduces itself." 27 Pleasure, then, is in the presentation of purposiveness of another mental state.

It is clear that pleasure is intentional, but how is pleasure also formal? In short, pleasure is formal because it concerns only the form of purposiveness. Since there is no particular content of pleasure, different things can act as the occasion on which pleasure is felt. The only thing that could act as a content of pleasure is the wanting to keep in mind the current presented object. This kind of formal structure is purposive in that it is future-directed, tending towards the continuation of the pleasure. The relation is between the awareness of a current mental state and a future mental state; and this particular kind of relationality is purposive because it seems to be directed towards, take as its purpose, a future mental state. This future mental state, however, cannot be found, it is not yet, or ever, at hand. Thus, the formal, relational structure of pleasure can be aptly described as purposiveness without purpose.

Putting this issue aside, however, Zuckert goes on to claim that only aesthetic pleasure, unlike pleasure in the agreeable or pleasure in the good, is truly purposive, and, in fact, purposive without purpose. Both agreeableness and pleasure in the good can be mis-described as "future-directed." To take the case of the good, this type of pleasure does seem to be purposive or tending towards some future state. But what is the motivation for this pleasure? Ideas of the good or concepts of some morally respectable state can cause us to act so that such a state arises. The desire to bring about the state of the good in some future time is rooted in a previous determinate judgment. Due to some past experience of this good, and due to the judgment that the recurrence or more general appearance of this good will bring about pleasure, I can will myself into those actions take cause the appearance of this future state. Thus, "willed activity involves conceptual 'foresight of the future effects of one's causal powers." 28 The pleasure in the good or the agreeable, then, refers to, or takes as its ground of possibility, the past. Thus, "in these two cases of pleasure, Kant ultimately understands pleasure as 'satisfaction' in the present, in terms of past aims... [they] presuppose something that precede [them]."29

Aesthetic pleasure, on the other hand, since it presupposes no concept of the beautiful, is constituted by nothing but purposiveness without a purpose. There is no goal or aim behind it or in front of it, just as there is no pain calling out for relief. There is no lack, or even a lack of a lack. Aesthetic pleasure is a pure positive swelling, a surprise, an unexpected site of joy; for it does not make sense to say, "I lack beauty," as one says "I am thirsty or hungry." Beauty is not something we have beforehand and seek to repeat.

${ }^{27}$ Kant, Critique of Judgment, \12; emphasis in the original.

${ }^{28}$ Zuckert, "A New Look" 246; Zuckert cleverly distinguishes between 'foresight' and 'presentiment.' While it is impossible to see (feel) the future - which is why pre-senti-ment, a feeling (senti) beforehand (pre) is problematic - one is able to pre-dict ('pre' as in before and 'dict' as in to say or determinatively judge) since concepts are universal, and thus are applicable to any present.

${ }^{29}$ Ibid., 247-248. 
Pleasure in an aesthetic object, rather, constitutes itself; it is its own causality. Pleasure is an awareness of a wanting to remain in this state of mind. There is a difference in the "lingering," then. While the good or the agreeable can discover a past state or fixed concept that directs or prompts the delaying in the current state, the pleasure in the aesthetic object presented to the subject is itself the cause of the wanting to tarry or linger: without an end in sight, it leads itself astray. Agreeableness and the good have a home or concept to return to, but aesthetic pleasure demurs, it loiters outside the home. The pleasure is purposive, hence the tarrying, but the goal is perpetually yet-to-be-found because it will never be found. In short, the pleasure dwells on this drawl, without drawing from any dwelling. Pleasure, then, is purposive without a purpose. Zuckert sums up the argument with eloquent concinnity:

\begin{abstract}
. . . instead of being directed toward a conceptually described object (determined by a concept in the past), instead of reflecting a change from a "past" state, aesthetic pleasure "prompts" a lingering in our current state, is the consciousness of ourselves as lingering in the present state, of the present state as a state of pure futuredirectedness. It is constituted by "purposiveness without a purpose."30
\end{abstract}

\title{
Sensus Communis and the Attunement of the Three Sites of Purposiveness
}

We have now seen how the principle of purposiveness without purpose can be located in three different places: in the object itself, in the gift of the object for the subject, and in the pleasure in the subject. It remains to be seen, however, how these three uses of purposiveness relate to the rest of the Analytic of the Beautiful, in general, and to the Deduction of Pure Aesthetic Judgments, in particular. It is my contention that the means for establishing this relationship is through the notion of sensus communis.

Kant claims that an aesthetic judgment is both universal and necessary, that such a judgment applies to all and necessarily so; but both the qualitative and the modal status of such a judgment "is still uttered only conditionally." 31 It seems, then, that if it is possible to locate and reveal this condition, then aesthetic judgments will be exactly what Kant claims them to be. This condition, which is a very unusual kind of condition, is revealed through an exploration of the sensus communis.

The first thing that must be done is to see how the sensus communis relates to the three sites of purposiveness without purpose. In order to do this one would assume that it is helpful to see how Kant himself defines the sensus communis. Unfortunately, Kant remains particularly bearded on this point.

\footnotetext{
${ }^{30}$ Ibid., 248.

${ }^{31}$ Kant, Critique of Judgment, $\$ 19$.
} 
Although the sensus communis does seem to play a crucial role in both the Analytic and the Deduction - it functions as the missing rule for the subjective necessity of judgments of taste and it plays a very important role in the deduction(s) ${ }^{32}$ - Kant seems to evade the issue by reverting to the Latin. This is not an uncommon Kantian tactic. When Kant seems to be particularly vague about a certain issue or concept, he often reverts to Latin. In fact, in the Third Critique he switches between the Latin sensus communis and the German Gemeinsinns (common sense) without any explanation for this interchange, thereby further compounding this ambiguity. ${ }^{33}$ Rather than shying away from this issue and passing over this lack of precision in silent but dismissive confusion, however, this is exactly where I will point my stylus and begin to explore. It seems that this gesture toward an undisturbed space is the perfect place to test the value and strength of the Third Critique. Let's begin with Kant's own definition and see where it leads.

Kant defines the sensus communis in at least three different ways. Two of these definitions appear in $\$ 20$. In the first paragraph of this section Kant views the sensus communis as a "subjective principle" that functions as the condition or ground for the necessary demand that others judge as the subject judges. The principle is merely subjective, and not objective, because it "determines only by feeling rather than by concepts." That is, there are no logical rules or proofs that can objectively demonstrate the universality and the necessity of aesthetic judgments. One might then suspect that Kant would explain this principle; but this is not the case. Rather, this is where Kant first reverts to the Latin. Kant leaves this principle undefined. To make matters more confusing, in $\$ 40$ Kant defines the sensus communis in yet another way. Now, it is no longer a principle, but a faculty or ability. To be precise, he defines the sensus communis as the faculty of taste itself. As Kant says, "taste can be called a sensus communis...and th[is] aesthetic power of judgment deserves to be called a shared sense." The sensus communis, then, seems to be the ability to judge an object, an ability that Kant often refers to as the power of estimation. As if this were not confusing enough, in the second paragraph of that $\$ 20$, Kant defines the sensus communis in a third way, namely, as a feeling or "effect arising from the free play of our cognitive powers" rather than as a principle or ability. This free play of the faculties of the imagination and the understanding, however, should be taken together with the account of the sensus communis as a principle and as an ability or faculty.

32 It is unclear as to how many deductions Kant actually intended to give. Daniel Crawford claims that there are five stages of one deduction. See Daniel W. Crawford's Kant's Aesthetic Theory, (Madison, WI: University of Wisconsin Press, 1974), 69-160 for more. Paul Guyer, however, contends that there are two deductions that are relatively independent of each other. See Paul Guyer Kant and the Claims of Taste, 256-331. Since the actual number of deductions is not crucial to my argument, I will not address this issue directly.

33 This is evidence of the common complaint of Kant being overly "technical without being precise," to use Henry Allison's own phrase, for the use of Latin is often referred to as false precision Allison, Kant's Theory of Taste, 120. 
The sensus communis now seems to be three different things at the same time. This, at least at first, might seem to leave Kant's theory of aesthetics in a precarious position. One would then expect that the most sophisticated and well-versed commentators would attempt to clarify this confusion. Both of these assumptions, however, are not confirmed. Almost all the commentators gloss over this issue without saying much more than repeating what Kant himself says. ${ }^{34}$ This willful negligence, however, will now end. The first way to begin to deal with this confusion and to take a new look at the sensus communis as the condition for aesthetic judgments is to go back to the three sites of purposiveness without purpose.

\section{The Mapping of the Sensus Communis onto the Three Sites of Purposiveness without Purpose}

To review, there are three senses of sensus communis: a principle, a faculty or ability, and a feeling; and there are three sites of purposiveness without purpose: in the object itself, in the object's gift to the subject, and in the pleasure in the subject. Each of the three terms in each list can be linked up with the corresponding term in the other list. This mapping of the three senses of sensus communis directly onto the three sites of purposiveness without purpose will allow Kant's theory to communicate and reflect itself from and through different points of the text, and it will allow the reader to see another way in which the whole thing hangs together. We will proceed in the order given.

The purposiveness in the object as represented is nothing other than the sensus communis defined as a principle. The object seems to be directed towards some end, but this end cannot be found. Despite this inevitable and indefinite loss the object occasions a certain structure that leads into the two other sites of purposiveness without purpose. This initial structure acts as a model that brings about a spark, beginning in the object, that arcs, along a fabric of purposiveness, to the subject. The subject, then, reflects on this gift and becomes aware of the pleasure in its own mental state. The same moving structure that is represented in the object, presented to the subject, and then picked up on by the subject, is a principle applicable to all three locations. Hence, the site of purposiveness without purpose in the object is the principle that first communicates to the other sites a shared meaning, a shared sense, a sensus communis. In this way, the principle is the unspoken structure that attunes (stimmt $)$ the rest of the sites of purposiveness. This principle is the principle of attunement (Einstimmung) that communicates to the faculties in the subject a certain proportion, a principled proportion.

The purposiveness of the object's gift to the subject must be able to be received by the subject. This means that the subject must have a certain ability or faculty by which this gift can be received. That is, there must be some ability

34 See Guyer's Kant and the Claims of Taste, Allison's Kant's Theory of Taste, and even Zuckert's Kant on Beauty and Biology. 
of the subject to cognize without determinate concepts, some faculty to accord with the purposiveness in the two other sites, some power to judge that conditions the harmonization of the other two senses of sensus communis. This means that the subject cannot cognitively recognize the present-ation of the object and then apply that same gift to other objects. One gift is not equivalent to another gift. The gift is not merely the instance of a kind. Moreover, as soon as there is the temptation to determine (bestimmen) the "type" of gift, (through an act of subsumption), the giver is gone, lost, running errantly. Rather, the gift is a way to bring the subject into a confrontation with the ends of human science and morality, or to be more precise, with the ends of subjectivity. Without the ability to receive the gift - namely, to judge aesthetically - the subject cannot pick up on a sort of meaning (sensus) that is not constituted (bestimmt) by the subject. Since the gift remains undetermined (unbestimmt) the gift cannot be conceptually understood; it cannot be moral or immoral. The gift can only be felt. Thus, as was said, Kant defines this faculty of picking up on the gift, of attuning to the principle of the gift, as taste itself, the ability to judge aesthetically, a practice of estimation.

Finally, given that the sensus communis as a principle of attunement (Einstimmung) can be mapped onto the purposiveness in the object, and given that the faculties must be able to become attuned (abstimmt) to the object and its gift, there must be some way for the subject to become aware of this attuning: namely, the subject attunes to this act of giving through a feeling (Stimmung), which means that that this is the site of the sensus communis seen as a feeling. ${ }^{35}$ The object re-presents the principle of purposiveness, but since this principle is merely a subjective principle, it must be felt. There is no recourse to concepts, no logical rule or proof can be found that would objectively ground the necessity and universality of aesthetic judgments. And it is in this feeling that the subject is attuned (abgestimmt) to another aspect of itself and the world. The structure (principle) of purposiveness without purpose is then aesthetically received as a gift that attunes (stimmt) the manifold of voices (Stimmen) to the same frequency. It is just that this frequency or tuning is too soft (beauty) or too loud (the sublime) for the domains of knowledge and ethics. As Kant says, "the only way this attunement [Einstimmung] can be determined [bestimmt] is by feeling [Gefühl." 36

To take a step back for a moment, pleasure, as Zuckert construed it, is both intentional and formal. She claimed that pleasure was a mental state "about," or took as its intentional object, another mental state. This other

35 As should be clear, this means, as Kant says in what he calls the "key" to the investigation of taste, that the judging comes before the pleasure. This is the "key" to the critique of taste because the precedence of the judgment before the feeling of pleasure is the only way for an aesthetic judgment to make universal claims.

36 Kant, Critique of Judgment, \$21. Although Kant uses Gefühl instead of Stimmung for 'feeling' in this quote, I believe that Stimmung is a more appropriate word. For Stimmung, besides this notion of attunement or determination, also means the mood, atmosphere, or ambiance of a certain place and time. Idiomatically, then, a certain feeling for a place means basically the ambiance or atmosphere. Hence, 'feeling' is another variation on Stimmung. 
mental state, the intentional object, was left relatively undefined. For whatever reason, she did not go into greater detail about this other mental state. We, however, are now in a position to say more about this intended mental state. This mental state is actually the reception of the gift and feeling arising from this act of reception. This feeling is nothing more than the effect of the harmony (Zuasammenstimmung) of the faculties. The consciousness of this feeling in the reception is, however, dependent on the ability to pick up on this feeling and the corresponding principle that is felt. The ability to judge, or taste as Kant defines it, is then one use of the sensus communis. Without this ability to attune (abstimmt) to the purposiveness without purpose in the gift as felt and the purposiveness without purpose in the object itself as a principle, one could not have aesthetic pleasure. "Hence, taste is our ability to judge a priori the communicability of the feelings that (without mediation by a concept) are in connection with a given presentation." 37 The sensus communis as the faculty of sensing the shared meaning of the principle of purposiveness without purpose is revealed to the subject through the sensus communis as aesthetic pleasure.

\section{Sensus Communis and the Deduction}

Kant suggests that the sensus communis, now seen as a certain attunement or attuning among the different sites of purposiveness, must serve as the condition for the universality and necessity of aesthetic judgments. In \$21, he goes so far as to claim that this attunement is necessary for turning representations into cognitions. This claim, that cognition and its universal communicability would not be possible if the faculties and the object were not harmonized or tuned to each other, strikes most readers as simply incomprehensible. ${ }^{38}$ Henry Allison, just to take a popular example, says "[t]here is simply no way in which a feeling resulting from the noncognitive condition of free play could serve as a condition of cognition." 39 Given the account that has been presented, this worry seems to dissipate. Is it really so problematic to claim that all cognition takes as its condition the free play of the faculties, which has been defined as this attuning of the faculties of the subject to the principle of purposiveness without purpose as it appears in the object? Keeping in mind that the faculty of judgment is itself the power of estimation, and that the attunement that we have mentioned is itself a sort of e-stim-ation of the object in itself without the recourse to concepts, then cognition seems to require this sort of estimation prior to determination.

One possible objection to this position is to claim that if the harmony of the faculties is a necessary condition for all experience, then Kant would be

37 Ibid., \ 40.

38 Anthony Saville contends that such an assumption of a sensus communis simply begs the question. See Anthony Saville, Aesthetic Reconstructions: The Seminal Writings of Lesing, Kant, and Schiller, 145-6, (NY: Blackwell Publishing, 1988), 185.

39 Allison, Kant's Theory of Taste, 153. 
committed to implausibly claiming that all types of experience actually contain aesthetic judgments in some sense. Such a worry, however, can be alleviated if one claims not that all objects are aesthetic, nor that all objects could be considered beautiful, which is a common response to this sort of objection; rather, it is to claim that all objects are potentially aesthetic. The question that might then be raised concerns how that potentiality is realized, how an object escapes the boundaries of cognition and morality. A way to answer this question (although I am ready to admit seeing the aesthetic potentiality in all things is not really a problem at all) is to claim that an object appears aesthetically or in an aesthetic light when one's stock of concepts fails, when they have become stale, or when they have lead into some problematic state of affairs. That is, an object escapes determination and emerges as aesthetic when those concepts fail to account for the form of some object. This indeterminate encounter, which is simply a way of "picking up" on the object rather than "taking up" the object as a member of this or that general type of thing, is a movement away or exsertion from the subject, and a return to the object. This sort of answer, it seems, assuages, if it does not completely refute, this objection concerning the implausibility of all experiences as containing aesthetic judgments.

In order to grasp the weight of the claim that the subject's faculties must be attuned to the form of the object, and that this attunement serves as the condition for cognition (and hence, if one could be so bold, for much of Kantian philosophy), let us situate the conversation so far in terms of what is said in the Deduction.

In $\$ 35$, only a few sections before the actual deduction of judgments of taste, Kant says something very arcane, but we should be careful not to let this statement merely pass away. A judgment of taste, Kant says, "can consist only in the subsumption of the very imagination under the condition [which must be met] for the understanding to proceed in general from intuition to concepts." ${ }^{40}$ This sentence seems to say, among other things, that the power of the imagination and the power of the understanding are not related in the determinative sense. These two faculties, rather, are set up, prepared for an act of legislation, held at the right tension for the eventual successful application of a concept. But in this wholly singular moment of contemplation, when no apposite concept can be found, when the only possible reaction is reflection on the play of the faculties, a certain harmony (Zuasammenstimmung) is reached.

This harmony is the moment of attunement, an instance of disparate parts of a heterogeneous manifold coming to vibrate on a shared plane. From this plane emerges a universal voice, different voices in choral harmony, a spontaneous song, a free (vaga) wandering together. There is an accord (Übereinstimmung) of chords (Akkorde). This is the condition of not only the ability for one to make a universal and necessary demand for others to judge together, but the condition for cognition in general, in particular, and in the relation between them. Here emerges the establishment of a ground of

${ }^{40}$ Kant, Critique of Judgment, $\ 35$. 
determinability (Bestimmbarkeit) prior to determination (Bestimmung). This groundless ground is structured by the principle of purposiveness without purpose, an a priori principle that is communicated to the subject through a feeling that is received through a faculty that is able to pick up on this sensation. One then lingers over this ground because of the meaning or sense that is echoed throughout the community of voices.

It is through this vibrating attunement that one is able to communicate with everyone, with all, with the universe: one speaks in a universal voice (Stimme) through a universe of voices calling each other out yet simultaneously listening to the other voices. This communicability is an exemplary convocation: the evocation and provocation of a univocity. The arrangement (Zusammen-stell-ung) of the object, the gift, and the subject stands in contrasting but complementary stances, voices acting in concert (zusammenarbeitend), standing as one (Zusammenstehend). This attuning of the different voices, from three different locations, is posthumously called the "condition" or seat of aesthetic judgment. This is a voice (Stimme or vocare) without logos, without law, without the understanding legislating deterministic laws of science, without the moral law legislating from the imperative seat to a kingdom of ends. The universal voice in aesthetic judgments is lawless, indeterminate, a pure sound attuning a continuous sense from the object to the subject through the faculties in harmonious play.

Perhaps the best way to understand this process - the way in which this attunement of the three sites of purposiveness through communication of a sensus communis functions as the condition for aesthetic judgment - is to consider the ways in which a musical instrument can be tuned in certain ways to set the conditions for the mood (Stimmung) created by the music. In order for a piano, for example, to play a particular song the tension of the strings must be properly aligned according to certain intervals or proportions. The vibrations of the strings allow a $\mathrm{C}$ major chord, for example, to ring out as the correct pitch. Without this initial attunement a particular song cannot be played. The condition for the actualization of a song must be met before the song can ring out. The piano tuner raises and lowers the pitches of the string until the desired relationship between pitches is reached. Yet the piano can also be tuned in different ways. With these different tunings come different possibilities for play. The case is very similar to the conditioning of aesthetic judgment and cognition. Without an initial attunement of the faculties in terms of the reception of the object, cognition cannot happen. Just as a piano requires that the proper proportion of intervals between strings for a song to be played, mental activity of whatever sort requires and presupposes a proper attunement of the faculties on a represented object.

Like the piano strings the setting of the faculties at the right proportions is a sort of pretheoretical orientation, an attunement that opens up the possibility for determination, which is nothing other than taste. Such a challenge to the order of human behavior, and especially to philosophy as a practice of calculated knowing and truth-only reasoning, occurs within the very term that hangs over our departmental doors. Consider what Nietzsche says 
about the title of our discipline. 'Philosophy' does not merely mean a love of or for wisdom or knowledge; rather, the Sophia or the Sage that the philosophy loves or at least is friendly to begins with taste. Nietzsche says, "[t]he Greek word 'sage' is etymologically related to sapio, I taste, sapiens, he who tastes, sisyphos, the man of keenest taste. A sharp savoring and selecting, a meaningful discriminating, in other words, makes out the peculiar art of philosophy." 41 Prior to knowledge, before any morality, there is taste.

\section{Conclusion}

This account of the use and structure of the concept of the accord in Kantian aesthetics, I suspect, might strike many contemporary readers of the general Kantian project as slightly radical. While there may be some truth to this charge, this reading does not detract from the force of the Third Critique. Rather the ability of a text to produce a diverse and wide-ranging set of readings attests to the importance of the work itself. In order to exploit the power of this third and last product of the three critical texts, I have attempted what might be called an inconstruction.

As I said above, an inconstruction is a way of using a thinker's set of concepts as melodies or conceptual structures that provide openings and opportunities for experimentation with sets of ideas or concepts. By working with some recent interpretations of the texts, especially Rachel Zuckert's exemplary work, I have shown how an inconstruction delves into and builds out of the arguments and claims already in play.

In this way, I have utilized a few of the most provocative and engaging concepts Kant ever produced in order to continue a process that I take Kant himself already to have initiated. To be exact, the Critique of Judgment, among other things, is nothing short of a rewriting of a few features of the famous transcendental aesthetic as it appears in the First Critique. By re-reading the ternary use of the concepts of purposiveness without purpose and the corresponding threefold use of the sensus communis in light of a re-thinking of the importance of attunement or harmony of the faculties, I have constructed into the Kantian corpus a rather forceful, if not slightly unKantian, claim. In short, in line with the Nietzsche reference above, aesthetics, for this reading of the Kantian corpus, is fundamental. For to claim that the harmonious attunement that characterizes an aesthetic judgment is necessary for cognition - in both morality and knowledge - is also a way of defining what it means to be a finite human being. Thus, if thinking or acting rationally presuppose a sort of aesthetic attunement, then aesthetics is indeed first philosophy.

Department of Philosophy, Duquesne University, United States of America

${ }^{41}$ Nietzsche, Friedrich, Pbilosopby in the Tragic Age of the Greeks (Regenery Publishing, 1962). 


\section{References}

Allision, Henry, Kant's Theory of Taste: A Reading of the Critique of Aesthetic Judgment (Cambridge, UK: Cambridge University Press, 2001).

Crawford, Donald W., Kant's Aesthetic Theory (Madison, WI: University of Wisconsin Press, 1974).

Derrida, Jacques, “Economimesis," in Diacritics, 11 (Summer, 1981), 3-25. , The Truth in Painting, trans. Geoff Bennington and Ian McLeod (Chicago: The University of Chicago Press, 1987).

Ginsborg, Hannah, "On the Key to Kant's Critique of Taste," in Pacific Philosophical Quarterly 72:4 (1991), 290-313.

"Purposiveness and Normativity," in Hoke Robinson ed., Proceedings of the Eighth International Kant Congress (Milwaukee: Marquette University Press, 1995), volume II, 453-460. "Reflective Judgment and Taste," in Nous 24:1 (1990), 63-78.

Guyer, Paul, Kant and the Claims of Taste (Cambridge, U.K.: Cambridge University Press, 1997).

Kant, Immanuel, Critique of Judgment, trans. by Werner S. Pluhar (Indianapolis: Hackett Publishing Company, 1987).

Lyotard, Jean-Francois, "Sensus Communis," in Judging Lyotard. (New York: Routeledge, 1992).

Nietzsche, Friedrich, Philosophy in the Tragic Age of the Greeks, trans. by Marianna Cowan (Washington D.C.: Regenery Publishing, 1962).

Pippin, Robert, "The Significance of Taste: Kant, Aesthetic, and Reflective Judgment," in The Journal of the History of Philosophy, 34:4 (1996), 549569.

Saville, Anthony, Aesthetic Reconstructions: The Seminal Writings of Lesing, Kant, and Schiller, 145-6, (NY: Blackwell Publishing, 1988),185.

Zuckert, Rachel, "A New Look at Kant's Theory of Pleasure," in The Journal of Aesthetics and Art Criticism. 60:3 Summer (2002), 239-252.

Kant on Biology and Beauty (Cambridge: Cambridge University Press, 2007).

"The Purposiveness of Form: A reading of Kant's Aesthetic Formalism," in Journal of the History of Philosophy, 44:4 (October, 2006) 599-622. 